Brit. J. Ophthal. (1960) 44, 570.

\title{
MENINGOCOELE OF THE OPTIC DISC*
}

\author{
BY
}

\author{
PETER WRIGHT \\ Royal Air Force, London
}

THE following case displays a congenital anomaly which, so far as I can discover, has not been previously described.

\section{Case Report}

A fit young man aged 26 was examined on June 13, 1959, to assess his suitability for service with the Royal Air Force. He was an experienced pilot with a total of 250 hours flying experience in all types of aircraft, including jets. No abnormality had been detected in any system at a previous examination.

Examination.-Visual acuity in the right eye was $6 / 4$ and in the left $6 / 6$, and $6 / 4$ with $+0.50 \mathrm{D}$ cyl., axis $180^{\circ}$. The ocular movements, ocular muscle balance, and accommodation were normal. The pupils were regular, equal, and reacted normally to light and near reflex. The media were clear, and the right fundus normal.

The left optic disc, however, showed a coloboma in its medial half with a steep nasal edge and a shelving pigmented lateral edge which gradually merged into the disc (Figure).

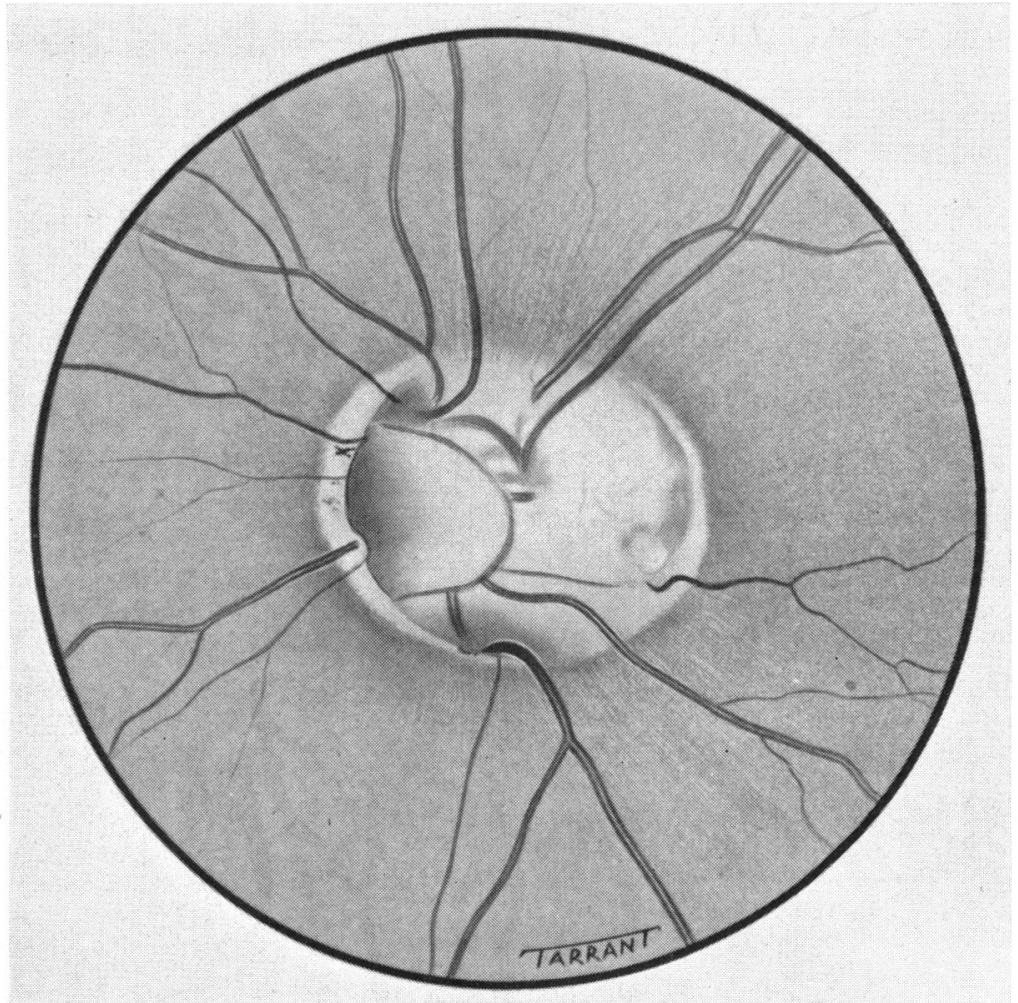

* Received for publication October 20, 1959. 
From the depths of this coloboma there appeared a diaphanous hernia, projecting obliquely forwards into the vitreous and pulsating synchronously with the carotid arteries. The apex of the hernial sac was slightly pigmented, but elsewhere it was quite transparent and very thin. The slightest pressure on the globe caused the hernia to collapse and gentle compression of the jugular veins in the neck caused a great increase in distension.

The central visual fields showed a generalized enlargement of the blind spot in the left eye, but no other abnormality. The peripheral fields were full.

General medical and E.N.T. examinations failed to reveal any abnormality.

\section{Comment}

The swelling projecting from the disc would seem to be an arachnoidal hernia in free communication with the intracranial subarachnoid space. In view of the extreme thinness of the sac it is of interest that this airman has frequently subjected himself to a force of several " $G$ " during flight with no ill-effects.

I am indebted to the Director-General of Medical Services, Royal Air Force, for permission to publish this case. 